\title{
Higher prevalence of lymph node metastasis in prostate cancer in patients with diabetes
}

\section{Dear Editor,}

Prostate cancer (PCa) and type 2 diabetes mellitus are under the most frequent diseases in men with a tremendous impact on morbidity and mortality (Giovannucci et al. 2010). Incidence of many common types of cancer is known to be higher in diabetes (Giovannucci et al. 2010). However, studies reported that incidence of PCa is not increased in men with type 2 diabetes, some studies even found reduced prevalence (Kasper et al. 2009). In contrast, PCa survival is markedly reduced in patients with coincident type 2 diabetes (Chen et al. 2017). The underlying molecular mechanisms for shortened survival are still under ongoing debate and not fully understood. They might include altered insulin or IGF-1 signaling and enhanced androgen receptor activity. Of note, diabetes and PCa share numerous risk factors, most importantly the nonmodifiable risk factor age and the modifiable risk factor obesity (Giovannucci et al. 2010). Although PCa incidence is not elevated in obese men, patients with excess bodyweight are reported to display higher cancer-related mortality (Ma et al. 2008). Carefully adjusted studies for these risk factors investigating the impact of diabetes on PCa outcomes and aggressiveness are sparse. To better understand why PCa-related survival is shortened in men with concomitant diabetes, we evaluated the relation of diabetes with TNM staging and an established PCa risk score (Mohler et al. 2016), independent of age and body weight.

Therefore, we studied 624 patients who were diagnosed with PCa and underwent a radical prostatectomy between June 2004 and September 2007 in the Department of Urology, University of Tübingen. Their diabetes status was evaluated from the hospital records or by patients' questionnaires, after patients gave consent. Of these, 74 men had type 2 diabetes. Information on the antidiabetic therapy is presented in Table 1 . As their age and BMI were higher than the mean of the patients without diabetes, we performed matching for these variables. Patients with history of another malignant tumor and type 1 diabetes were excluded. Two patients without diabetes were matched to each patient with diabetes applying propensity score matching, using the nearest match method of the MatchIt package in R (R Project for Statistical Computing, Vienna, Austria). Thus, 222 participants were included (74 patients with diabetes and 148 men without diabetes). As intended, they were comparable in age and BMI (median age (year) (interquartile range): 65 (49-75) and 65 (51-75); median BMI $\left(\mathrm{kg} / \mathrm{m}^{2}\right): 28.4(22.5-57.5)$ and 28.4 (22.6-46.1), respectively). Gleason score and TNM status were carefully ascertained by an experienced pathologist. The Ethics Committee of the University of Tübingen approved the protocol.

The risk classification tool risk score based on the T-stage, Gleason score, PSA level (ng/mL) and N-stage was used as proposed by the National Comprehensive Cancer Network (NCCN) (Mohler et al. 2016). According to this, patients were stratified into 4 groups: low- (T1-T2a or Gleason score $\leq 6$ or PSA $<10 \mathrm{ng} / \mathrm{mL}$ ), intermediate-(T2b-T2c or Gleason score 7 or PSA $10-20 \mathrm{ng} / \mathrm{mL}$ ), high- (T3a or Gleason score $8-10$ or PSA $>20 \mathrm{ng} / \mathrm{mL}$ ), and very high- (T3b-T4 or N1) risk groups.

Non-normally distributed parameters were logtransformed prior to analyses. Groups were compared by $\chi^{2}$ or unpaired two-tailed $t$-tests. $P$ values $<0.05$ were considered significant. The statistical software package JMP 11.0 (SAS Institute Inc, Cary, NC, USA) was used.

We found that patients with diabetes displayed no significant difference in serum PSA levels or Gleason scores compared to patients without diabetes (all $P>0.2$ ).

The entire distribution of the PCa risk score (NCCN) was not significantly different between men with and without diabetes $(P=0.7)$. However, the proportion of patients in the very high-risk group was significantly greater among patients with diabetes $(P=0.028,20 \%$ vs $9 \%$, Fig. 1A). 
Table 1 Antidiabetic therapy in patients with diabetes.

\begin{tabular}{lr}
\hline Drug class & \\
\hline Insulin (\%) & \\
Metformin (\%) & 54 \\
Sulfonylurea/repaglinid/nateglinid (\%) & 15 \\
DPP4 inhibitor (\%) & 3 \\
Alpha-glucosidase inhibitor (\%) & 3 \\
\hline
\end{tabular}

While the T-stage was not different between the two groups $(P=0.3)$, analysis of the $\mathrm{N}$-score revealed significant difference. Only $1 \%(2 / 148)$ of the non-diabetic patients had lymph node metastasis, while $10 \%$ (7/74) of men with diabetes already had infiltrated lymph nodes at the time of operation (Fig. 1B). In our data set, this results in a calculated odds ratio of diabetes for lymph node metastasis of 7.63 .

Thus, we detected more aggressive tumors in men with diabetes, independent of age and body weight, as indicated by higher risk score and larger proportion of lymph node metastasis.

Abdollah and coworkers previously reported higher Gleason scores in diabetes (Abdollah et al. 2011). We could not reproduce this finding, possibly due to our careful matching for age and BMI, that has not been performed previously. Nevertheless, also in our study, two other parameters indicated more aggressive PCa in type 2 diabetes, namely the NCCN risk score and the N-stage. Though, N-stage is one criterion to calculate NCCN risk score. At least the latter one was suggested to be higher in diabetes in a previous report (Kronig et al. 2017). However, as obesity is a risk factor for lymph node metastasis in PCa (Schnoeller et al. 2015), higher body weight in diabetes could have confounded earlier analyses. We now excluded this possibility and ascertained more frequent lymph node infiltration in diabetes independent of body weight. Thus, our findings may indicate that known shorter PCa survival in men with diabetes could be due to more aggressive tumors. This should further be tested in prospective studies.

A number of molecular mechanisms can underlie these findings: As PCa is an androgen-dependent tumor, circulating and in particular intraprostatically synthesized androgens are in focus of current investigations. Very recently, we demonstrated an augmented gene expression machinery of the androgen receptor (AR) and downstream target genes underscoring activity of this signaling cascade

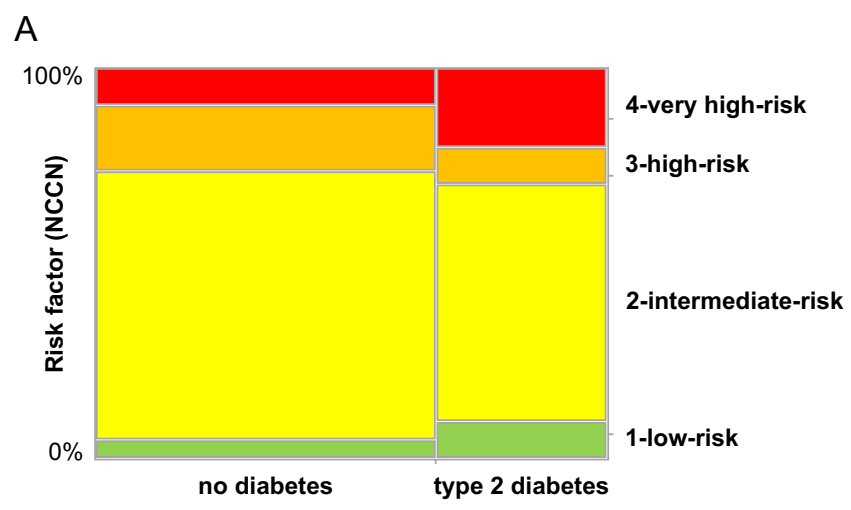

B

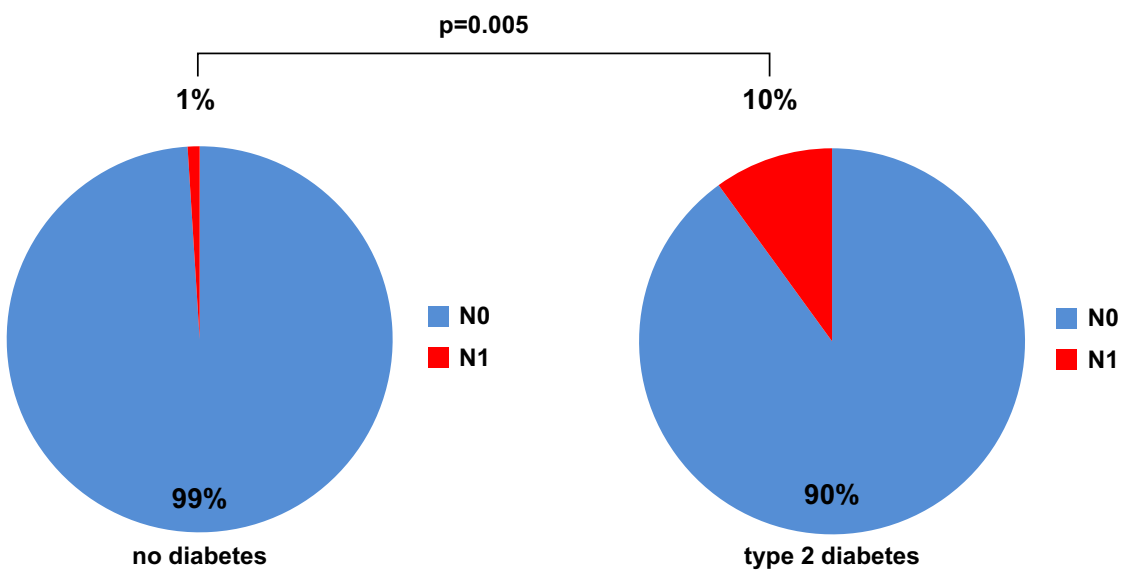

\section{Figure 1}

(A) Distribution of the NCCN risk score in patients with and without diabetes. For each of the 74 patients with type 2 diabetes and the 148 men without diabetes, the National Comprehensive Cancer Network (NCCN) risk score was calculated. The relative distribution thereof is presented in the figure. (B) Prevalence of lymph node metastasis in patients with and without type 2 diabetes. Presented is the relative prevalence of lymph node metastasis at the time of radical prostatectomy in the 74 patients with type 2 diabetes and the 148 men without diabetes. Groups were compared by $\chi^{2}$ test. 
in patients with diabetes (Lutz et al. 2017). Of note, the activity of the androgen chain in diabetes was detected despite of the known reduction of testosterone in this patient group.

It is a well-known phenomenon that insulin levels are elevated in type 2 diabetes, either to compensate insulin resistance or because of insulin-elevating therapies. We recently showed altered composition of insulin or IGF-1 receptors that favor the mitogenic isoforms in PCa (Heni et al. 2012). Hence, elevated insulin might promote tumor growth in diabetes.

Furthermore, hyperglycemia is a hallmark of diabetes. Men with higher blood glucose levels have more aggressive prostate cancer (Kim et al. 2010). Thus, more glucose availability may represent another pathomechanistic way toward more aggressive tumors and worse outcome.

One limitation of the study is that we have no evaluation of glycemic control or diabetes duration, i.e. time from diabetes diagnosis to surgery, of the included patients. Furthermore, no systematic follow-up of patient history was available. The applied NCCN risk score depends on status of lymph node metastasis and is therefore unable to address tumor aggressiveness independent of lymph node involvement. We can furthermore not exclude that different time of diagnosis in patients with and without diabetes might have influenced our results, even if comparable PSA levels argue against this possibility.

In conclusion, we report higher prevalence of lymph node metastasis and more high-grade tumors in men with PCa and coexistent type 2 diabetes. These findings may in part explain the worse outcome in patients with type 2 diabetes. Further studies should test the implication of our results for the antidiabetic as well as the antitumor therapies of patients with PCa and type 2 diabetes. They may pave the way toward more personalized treatment of this malignancy.
${ }^{1}$ Department of Internal Medicine, Division of Endocrinology, Diabetology, Vascular Disease, Nephrology and Clinical Chemistry, University of Tübingen, Tübingen, Germany 2Institute for Diabetes Research and Metabolic Diseases (IDM) of the Helmholtz Center Munich, University of Tübingen, Tübingen, Germany

${ }^{3}$ German Center for Diabetes Research (DZD), Munich-

Neuherberg, Germany

${ }^{4}$ Department of Urology, University of Tübingen, Tübingen, Germany

Institute of Pathology, University of Tübingen, Tübingen, Germany

'Institute of Clinical Epidemiology and applied Biostatistics, University of Tübingen, Tübingen, Germany 7Institute of Pharmaceutical Sciences, Department of Pharmacy and Biochemistry, University of Tübingen, Tübingen, Germany

(Correspondence should be addressed to H-U Häring: hans-ulrich.haering@med.uni-tuebingen.de)

Declaration of interest

The authors declare that there is no conflict of interest that could be perceived as prejudicing the impartiality of this article.

\section{Funding}

The study was supported in part by a grant from the German Federal Ministry of Education and Research (BMBF) to the German Center for Diabetes Research (DZD e.V.).

\section{Author contribution statement}

The study was designed by $\mathrm{M} \mathrm{H}, \mathrm{A} \mathrm{F}$ and $\mathrm{H} \mathrm{U} \mathrm{H}$. Data acquisition was performed by $\mathrm{J} \mathrm{H}, \mathrm{MOS}$ and $\mathrm{M} \mathrm{H}$. Data analysis and interpretation was done by $\mathrm{R} \mathrm{W}$, J M F, S Z L, T T, H U H, P M and M H. S Z L drafted the manuscript. $\mathrm{R} \mathrm{W}, \mathrm{J} \mathrm{H}, \mathrm{A} \mathrm{F}, \mathrm{T} T, \mathrm{M} \mathrm{H}, \mathrm{A} S$ and $\mathrm{H} \mathrm{U} \mathrm{H}$ contributed to the discussion. All authors revised the manuscript and approved the final version to be published.

Stefan Zoltán Lutz ${ }^{1,2,3}$

Tilman Todenhöfer ${ }^{4}$

Robert Wagner ${ }^{1,2,3}$

Jörg Hennenlotter ${ }^{4}$

Jana Marlene Ferchl ${ }^{1}$

Marcus Oliver Scharpf ${ }^{5}$

Peter Martus 6

Harald Staiger $2,3,7$

Andreas Fritsche ${ }^{1,2,3}$

Arnulf Stenzl ${ }^{4}$

Hans-Ulrich Häring1,2,3

Martin Heni ${ }^{1,2,3}$

\section{Acknowledgements}

The authors thank all study participants for their cooperation. They gratefully acknowledge the excellent technical assistance of Anja Dessecker and Ursula Kühs.

\section{References}

Abdollah F, Briganti A, Suardi N, Gallina A, Capitanio U, Salonia A, Cestari A, Guazzoni G, Rigatti P \& Montorsi F 2011 Does diabetes mellitus increase the risk of high-grade prostate cancer in patients undergoing radical prostatectomy? Prostate Cancer and Prostatic Diseases 14 74-78. (https://doi.org/10.1038/pcan.2010.41) (c) 2018 Society for Endocrinology Published by Bioscientifica Ltd. Printed in Great Britain 
Chen Y, Wu F, Saito E, Lin Y, Song M, Luu HN, Gupta PC, Sawada N, Tamakoshi A, Shu XO, et al. 2017 Association between type 2 diabetes and risk of cancer mortality: a pooled analysis of over 771,000 individuals in the Asia Cohort Consortium. Diabetologia 60 1022-1032. (https://doi.org/10.1007/s00125-017-4229-z)

Giovannucci E, Harlan DM, Archer MC, Bergenstal RM, Gapstur SM, Habel LA, Pollak M, Regensteiner JG \& Yee D 2010 Diabetes and cancer: a consensus report. Diabetes Care 33 1674-1685. (https://doi. org/10.2337/dc10-0666)

Heni M, Hennenlotter J, Scharpf M, Lutz SZ, Schwentner C, Todenhofer T, Schilling D, Kuhs U, Gerber V, Machicao F, et al. 2012 Insulin receptor isoforms A and B as well as insulin receptor substrates-1 and -2 are differentially expressed in prostate cancer. PLOS ONE 7 e50953. (https://doi.org/10.1371/journal.pone.0050953)

Kasper JS, Liu Y \& Giovannucci E 2009 Diabetes mellitus and risk of prostate cancer in the health professionals follow-up study. International Journal of Cancer 124 1398-1403. (https://doi. org/10.1002/ijc.24044)

Kim HS, Presti JC Jr, Aronson WJ, Terris MK, Kane CJ, Amling CL \& Freedland SJ 2010 Glycemic control and prostate cancer progression: results from the SEARCH database. Prostate 70 1540-1546. (https:// doi.org/10.1002/pros.21189)

Kronig M, Haverkamp C, Schulte A, Heinicke L, Schaal K, Drendel V, Werner M, Wetterauer U, Schultze-Seemann W \& Jilg CA 2017
Diabetes and beta-adrenergic blockage are risk factors for metastatic prostate cancer. World Journal of Surgical Oncology 15 50. (https://doi. org/10.1186/s12957-017-1117-4)

Lutz SZ, Hennenlotter J, Scharpf MO, Sailer C, Fritsche L, Schmid V, Kantartzis K, Wagner R, Lehmann R, Berti L, et al. 2017 Androgen receptor overexpression in prostate cancer in type 2 diabetes. Molecular Metabolism [epub]. (https://doi.org/10.1016/j. molmet.2017.11.013)

Ma J, Li H, Giovannucci E, Mucci L, Qiu W, Nguyen PL, Gaziano JM, Pollak M \& Stampfer MJ 2008 Prediagnostic body-mass index, plasma C-peptide concentration, and prostate cancer-specific mortality in men with prostate cancer: a long-term survival analysis. Lancet Oncology 9 1039-1047. (https://doi.org/10.1016/S14702045(08)70235-3)

Mohler JL, Armstrong AJ, Bahnson RR, D'Amico AV, Davis BJ, Eastham JA, Enke CA, Farrington TA, Higano CS, Horwitz EM, et al. 2016 Prostate cancer, version 1.2016. Journal of the National Comprehensive Cancer Network 14 19-30. (https://doi.org/10.6004/ jnccn.2016.0004)

Schnoeller TJ, Steinestel J, Zengerling F, Schrader AJ \& Jentzmik F 2015 Serum 17beta-estradiol fails as a marker in identification of aggressive tumour disease in patients with localized prostate cancer World Journal of Urology 33 1979-1984. (https://doi.org/10.1007/ s00345-015-1567-7)

Received in final form 20 December 2017

Accepted 4 January 2018 (c) 2018 Society for Endocrinology Published by Bioscientifica Ltd. Printed in Great Britain 